\title{
DETECTION OF SOYBEAN BY REAL-TIME PCR IN THE SAMPLES SUBJECTED TO DEEP TECHNOLOGICAL PROCESSING
}

\author{
Konstantin A. Kurbakov^, Evgenii A. Konorov, Valentina N. Zhulinkova, Mihail Yu. Minaev \\ V. M. Gorbatov Federal Research Center for Food Systems of Russian Academy of Sciences, Moscow, Russia
}

Key words: real-time PCR, Glycine max, species identification, food processing, DNA degradation

\begin{abstract}
During deep technological processing, DNA of food product components (specifically, in canned foods) is subjected to strong degradation, which makes the PCR-based food components identification more difficult. In this work, a primer-probe system is proposed, which was selected for the multi-copy region of long terminal repeat (LTR) of soybean (Glycine max). We confirmed its high sensitivity and specificity for soybean detection by real-time PCR. Using the selected system, we successfully analyzed the samples of meat-and-plant canned foods and other food products subjected to deep technological processing - tofu, preserved tofu, soy sauces, confectionary products containing soy lecithin. To compare with these samples, real-time PCR was carried out using the primer-probe system selected for the single-copy le1 gene. In terms of sensitivity, the use of the primer-probe system specific to the single-copy region was significantly inferior to the primer-probe system specific to the LTR region. The difference in the rate of degradation of these genomic DNA regions of Glycine max was found.
\end{abstract}

\section{Introduction}

Soybean and products of its processing are widely used in the food industry. This category of raw materials is often used for meat product falsification (replacing part of meat raw materials or exceeding a quantity specified in TS). It is also necessary to note that soybean is an allergen and one of the main cultures subjected to genetic modification.

At present, several methods have been developed to detect soybean in foods. Methods based on the polymerase chain reaction (PCR) and enzyme-linked immunosorbent assay (ELISA) are applied most frequently. Soy proteins are also used in manufacturing products that have undergone deep technological processing (canned foods, fermented products). In this case, both DNA and proteins are subjected to strong degradation, which reduces sensitivity of these methods [1,2].

As soybean is an allergen, several authors choose the lectin gene (le1) to develop methods for PCR identification of soybean. The lectin gene is presented by a single copy in genomic DNA. Therefore, sensitivity of the method can be insufficient when analyzing certain samples. This constraint can be overcome by digital PCR with higher sensitivity compared to other PCR methods [3]. Primers specific to the lectin gene are used mainly in multiplex test systems of quantitative detection of GMO by digital PCR $[2,4]$.

To increase PCR sensitivity, multicopy DNA markers are used, in particular, DNA of organelles: mitochondrial [5] or plastid [6]. This approach in combination with highly effective DNA extraction enables identification of a targeted matrix in low concentrations in deep processed samples [7]. However, in this case, time and expenditures for analysis are increased.

Retrotransposons are promising DNA regions for primer design when analyzing products that have undergone deep technological processing. Their main advantage is multiple copies. For example, Ballin et al. used the elements called the chicken repeat 1 (CR1) with the copy number of approximately 26,650 in the chicken genome and the trinucleotide repeat containing 5 (TNRC5) with the copy number of approximately 100,000 in the pork genome for comparative quantitative assessment of pork and poultry meat in the model samples [8]. This approach had high theoretical sensitivity of the method. However, the practical limit of detection (LOD) was restricted to $0.01 \%$ chicken in pork and $1 \%$ pork in chicken. This was explained by nonspecific interspecies amplification at the last cycles. The authors noted that predicted copy numbers of the targeted region in the pig genome were higher than the real ones by the order of magnitude. This was caused by nonspecific annealing of the developed primers on other regions of the genome. Therefore, the use of these regions was necessary for designing a primer system.

Retrotransposons are mobile genetic elements, which are most often represented in the eukaryotic genome by a large number of copies. Due to an absence in their composition of genes that are functionally significant for the organism, retrotransposons rapidly accumulate substitutions and, consequently, diversify. Moreover, part of retrotransposons are endogenous retroviruses, which allows suggesting that its own retrotransposon can appear in a taxon of any level due to insertion of a retrovirus into the genome and the following loss of its ability to develop virus particles. Because of this, an advantage of using these regions is low probability of non-specific annealing of primers for DNA of closely related species. To identify soybean, Yamakawa et al. [9] used primers for the retrotransposon. Detection of amplification products was carried out using gel electrophoresis. Specificity was controlled using 11 related (legume) and 16 other species 
of plants. The limit of detection (LOD) of non-degraded DNA was $0.001 \%$. A critical factor for the development of the PCR test-systems is a length of an amplicon. The longer an amplicon, the higher a probability of breakage at this DNA region under an effect of a technological process [10,11,12]. For real time PCR, a length of 100-150 nucleotide bases is considered optimal.

In the present work, we developed a primer-probe system for identification of soybean in products with its low content and in products that have undergone deep thermal processing. The primer-probe system was complimentary to the long terminal repeat (LTR) 83118-re-1 [13]. The products that were subjected to deep technological processing were analyzed. For comparison, parallel analyses with primers for the single-copy lectin gene were carried out.

\section{Materials and methods}

Objects of the research

Soy flour was used as a positive control. Flour produced from samples of pea, kidney bean and chickpea was a negative control. The samples were taken from the collection of the Laboratory of molecular biology and bioinformatics of the V. M. Gorbatov Federal Research Center for Food Systems of Russian Academy of Sciences. The following food products available in the retail chains were taken as test samples: four articles of canned meat-and-plant pastes (code designation P1-P4), six articles of meat-and-plant canned foods (C1-C6). To compare an effect of other technological processes on DNA degradation, samples of tofu, preserved tofu and three samples of soy sauces (S1-S3) were taken as well. We also analyzed four samples of confectionary products that contained soy lecithin (Con1-Con4) to assess a possibility of the method to detect soybean components that have undergone deep technological processing in food product samples.

As a positive control of soybean degraded DNA, we prepared a sample of soy flour that was diluted in distilled water in a ratio of 1:4 by mass. The obtained paste was treated in an autoclave in a glass vial at a temperature of $120^{\circ} \mathrm{C}$ for $20 \mathrm{~min}$.

\section{Sampling and DNA extraction}

Food products were minced in a knife mill GRINDOMIX GM 200 (Retsch, Haan, Germany). For DNA extraction, food product samples and control samples of $50 \mathrm{mg}$ each were taken. To extract DNA from the positive control of degraded DNA, $200 \mathrm{mg}$ were taken. After that, lysis and purification with chloroform were performed using the reagent kit Sorb-GMO-B (Syntol, Moscow, Russia) according to the instruction. The following DNA extraction was carried out using the MagNA Pure LC2.0 isolation station (Roche) with MagNa Pure LC DNA Isolation Kit II (tissue) (Roche, Mannheim, Germany).

\section{Primer design}

The primer-probe systems were complementary to the regions of le1 and long terminal repeat (LTR) 83118-re-1 (Table 1) available in the GenBank database [14]. For system design, the programs Primer-BLAST [15] and OligoAnalyzer v. 3 were used [16].

Real-time PCR

Real-time PCR was carried out using an amplifier ANK-32 (Syntol, Moscow, Russia). The reaction mixture with a volume of $30 \mu \mathrm{l}$ contained primers with a concentration of $300 \mathrm{nM}$, a probe with a concentration of $150 \mathrm{nM}, 2.5 \mathrm{mM}$ $\mathrm{MgCl} 2$, dNTPs with a concentration of $0.25 \mathrm{mM}$ each, SynTaq polymerase with a concentration of 2.5 activity units and $5 \mu \mathrm{L}$ of extracted DNA. The components of the reaction mixture were produced by Syntol. The parameters of PCR were the following: initial denaturation at $95^{\circ} \mathrm{C}$ for $7 \mathrm{~min}$ and 45 cycles of amplification $\left(60^{\circ} \mathrm{C}, 40 \mathrm{~s}\right.$ and $\left.95^{\circ} \mathrm{C}, 15 \mathrm{~s}\right)$. All samples were investigated in triplicate. The obtained data were analyzed using the software ANK-32 (Syntol). Statistical analysis was carried out with the use of Microsoft Excel 2016 [17].

\section{Results and discussion}

Detection of efficiency, specificity and cut-off cycles

To detect the reaction parameters and detection limit, PCR with selected primer pairs was performed. For analysis of primers for the lel gene, soybean DNA and its decimal dilutions up to $0.001 \%$ were used. For analysis of primers for the region 83118-re-1, we used a dilution of DNA extracted from soy flour with concentration of $10 \%$ to $0.0001 \%$.

The limit of detection in PCR with primers for lel was $0.01 \%$ of the targeted matrix in a sample. The calculated coefficient of correlation of PCR with primers for lel was $\mathrm{R} 2=0.99$; PCR efficiency was $\mathrm{E}=85.5 \%$. The equation of linear regression is the following:

$$
y=-4.295 x+49.01
$$

The calculated coefficient of correlation of PCR with primers for 83118-re-1 was R2 =0.99; PCR efficiency was

Table 1. Sequences and positions of the primers used in the study

\begin{tabular}{|l|l|c|}
\multicolumn{1}{|c|}{ Primer } & \multicolumn{1}{|c|}{ Primer sequence $\left(5^{\prime} \rightarrow 3^{\prime}\right)$} & $\begin{array}{c}\text { Amplification } \\
\text { region }\end{array}$ \\
\hline Lec1-F & CTCTACTCCACCCCCATCCA & \\
\hline Lec1-R & ATCTGCAAGCCTTTTTGTGTCAG & lification \\
size, bp
\end{tabular}


$\mathrm{E}=98.0 \%$. The equation of linear regression is the following:

$$
y=-3.4267 x+50.63
$$

When using Lec1, there was no non-specific annealing with samples of chickpea, kidney beans and pea, as well as in the negative control without DNA. When using primers for 83118-re-1, the threshold cycle (Cq) for all negative controls was $36.5 \pm 1.4$ (presented as the mean \pm standard deviation, $\mathrm{N}=18$ ) and was equal to $\mathrm{Cq}$ of the reaction without DNA addition $(36.3 \pm 0.05, \mathrm{~N}=3)$. Therefore, the cut-off cycle for the reaction with Gly_MAX was the 34th cycle, and the practical limit of detection was $0.001 \%$ of non-degraded DNA. The obtained values are comparable with the primers used in the work of Yamakawa et al. [9].

\section{Analysis of food products}

In the world market, as a rule, food products containing soy components are subjected to fermentative (tofu, soy sauces) and thermal treatment (confectionary products, bakery products). For quantitative detection of soybean content in products of deep processing, several authors proposed corresponding models of DNA degradation: a temperature regime $[4,10,18]$, enzyme treatment [19] and combination of an impact of a temperature and $\mathrm{pH}$ value $[11,19]$. The recipe of the model objects and temperature regimes were selected with consideration for the baking technology. For the Russian market, however, a study of canned foods is topical. To assess an effect of sterilization on DNA, DNA of soy flour after autoclaving was taken as a positive control. The Cq values of this sample were lower than in $1 \%$ of non-degraded DNA (Table 2). This suggests a significant effect of sterilization regimes on DNA. When using the primer-probe system Lecl, a difference between values $\mathrm{Cq}(\Delta \mathrm{Cq})$ of $1 \%$ soybean DNA and $100 \%$ degraded DNA was 8.08 cycles, while $\Delta C q$ of the same samples was 2.34 when the primer-probe system Gly_MAX was used (Table 2). Therefore, the primer-probe system Gly_MAX has higher comparative sensitivity in analysis of samples that have undergone technological processing. The calculated sensitivity for this model of degradation ensures the calculated sensitivity of $0.1 \%$ soybean in a sample.

During the investigation, soybean DNA was not revealed in the samples C3-C6, which corresponded to the declared composition. The results of real-time PCR of other samples are presented in Table 2. Soybean was found in the paste samples and sample $\mathrm{C} 1$ with the use of both primer-probe systems: Lec1 and Gly_MAX. In these samples, soybean was declared in the product composition, but it was not the main component. The Cq values obtained in real-time PCR were close to the positive control of DNA of $100 \%$ autoclaved soybean. In this semi-quantitative analysis, however, it is necessary to select a model of DNA degradation that corresponds to the studied sample. When studying the sample $\mathrm{C} 2$, soybean was detected with the use of the prime-probe system Gly_MAX, while real-time PCR with the use of Lecl gave a positive result only in two of three replicates. Soybean was not declared in the composition of this product.

Table 2. The result of PCR in the control samples and food samples with the use of the primers specific to the lel gene (Lecl) and LTR83118-re-1 (Gly_MAX)

\begin{tabular}{|c|c|c|c|}
\hline & \multicolumn{2}{|c|}{ Result of ampification, $\mathrm{Cq}$} & \multirow{2}{*}{$\begin{array}{c}\Delta \text { Cq between } \\
\text { Leq1 and } \\
\text { Gly_Max }\end{array}$} \\
\hline & Leq1 & Gly_Max & \\
\hline \multicolumn{4}{|l|}{ Control samples } \\
\hline Soybean $1 \%$ & $28.14 \pm 0.11^{\mathrm{a}}$ & $18.26 \pm 0.03^{a}$ & 9.88 \\
\hline $\begin{array}{l}\text { Soybean } 100 \%, \\
120^{\circ} / 20 \mathrm{~min}\end{array}$ & $36.22 \pm 0.63^{a}$ & $20.6 \pm 0.09^{\mathrm{a}}$ & 15.62 \\
\hline \multicolumn{4}{|l|}{$\begin{array}{l}\text { Meat-and-planned } \\
\text { canned foods }\end{array}$} \\
\hline P1 & $32.6 \pm 0.37^{\mathrm{a}}$ & $20.58 \pm 0.04^{\mathrm{a}}$ & 12.02 \\
\hline P2 & $33.49 \pm 0.19^{a}$ & $20.68 \pm 0.11^{\mathrm{a}}$ & 12.82 \\
\hline P3 & $33.63 \pm 0.26^{a}$ & $21.19 \pm 0.05^{\mathrm{a}}$ & 12.44 \\
\hline P4 & $34.71 \pm 0.04$ & $22.64 \pm 0.03^{a}$ & 12.07 \\
\hline $\mathrm{Cl}$ & $35.31 \pm 0.3^{\mathrm{a}}$ & $20.27 \pm 0.07^{\mathrm{a}}$ & 15.04 \\
\hline $\mathrm{C} 2$ & $37.63 \pm 0.71^{b}$ & $29.21 \pm 0.07^{a}$ & \\
\hline Preserved tofu & $36.16 \pm 1.43^{\mathrm{a}}$ & $21.8 \pm 0.04^{\mathrm{a}}$ & 14.36 \\
\hline Tofu & $26.28 \pm 0.04$ & $14.0 \pm 0.02$ & 12.28 \\
\hline \multicolumn{4}{|l|}{ Soy sauces } \\
\hline S1 & NR & $31.9 \pm 0.15^{\mathrm{a}}$ & \\
\hline S2 & NR & $31.37 \pm 0.11^{\mathrm{a}}$ & \\
\hline S3 & NR & $30.25 \pm 0.02^{\mathrm{a}}$ & \\
\hline \multicolumn{4}{|l|}{$\begin{array}{l}\text { Confectionary } \\
\text { products }\end{array}$} \\
\hline Con 1 & 37.55 & $29.6 \pm 0.1^{\mathrm{a}}$ & \\
\hline Con2 & $28.26 \pm 1.43^{a}$ & $17.9 \pm 0.9^{a}$ & 10.32 \\
\hline Con3 & $37.80 \pm 0.02^{b}$ & $31.14 \pm 0.19$ & \\
\hline Con 4 & NR & $33.3 \pm 0.38^{\mathrm{a}}$ & \\
\hline Con5 & 37.37 & $31.95 \pm 0.13^{a}$ & \\
\hline
\end{tabular}

The Cq values are presented as: the arithmetic mean \pm standard deviation $(\mathrm{a}-\mathrm{N}=3, \mathrm{~b}-\mathrm{N}=2), \mathrm{NR}-$ negative result

In production of tofu, soybean raw materials are heated at $85-110^{\circ} \mathrm{C}$ in the acidic environment [20]. In this process, DNA is also subjected to significant degradation [11]. During the investigation, a decrease in a quantity of nondegraded DNA was found (table 2). For example, the Cq value for preserved tofu was comparable with the results of the analysis of meat-and-plant canned foods. With that, Yamakawa et al. failed to detect specific DNA in thermally treated (fried) tofu [9].

Soy sauces are produced by long fermentation. This leads to a significant degradation of DNA and proteins. A majority of developed PCR and ELISA methods do not detect the presence of soybeans in a soy sauce. With that, this product retains its allergenicity [21]. In our work, PCR with the primers Gly_MAX gave a positive result. This is in agreement with the data of Yamakawa et al., who used primers for the retrotransposon region in their work [9].

In the samples of the confectionary product Con2, soy flour was declared in the composition. Its presence was successfully confirmed in PCR with both primer pairs. In the samples Con1, Con2 and Con5, soy lecithin was declared 
in the composition. In the sample Con4, soy components were not indicated on the label. In analysis with the primers Gly_MAX, soybean was found in all samples. In analysis with the primers Lecl, a positive result was observed in the samples Con1 and Con 5 only in one of three replicates, in the sample Con3 in two. The result of PCR with the primers Lecl was negative in the sample Con 4.

An effect of temperature regimes on a degree of degradation of different genome regions.

DNA degradation has a non-linear character depending on a technological process, for example, with an increase in time of exposure to a certain temperature [10]. Therefore, for quantitative assessment, it is necessary to know precise parameters of a technological process, which is impossible in practice. Mano et al. developed an index of DNA fragmentation based on the results of PCR of a targeted product with several primer pairs giving different length of amplicons [10]. However, the authors applied this index only for calculating the detection limit of the reaction for a certain sample and not for quantitative assessment of targeted DNA.

It was found during the investigation of control samples and products that a rate of degradation of the lel gene region was higher than those of LTR83118-re-1. It is well seen when comparing the difference in values $\mathrm{Cq}(\Delta \mathrm{Cq})$ obtained in PCR of the sample with the primers Lecl and Gly_MAX (Table 2). For example, in analysis of positive controls, $\Delta \mathrm{Cq}$ for the control sample of non-degraded $1 \%$ soybean was 9.88 ; while for the control sample of degraded DNA, it was 15.62.

The obtained value $\Delta \mathrm{Cq}$ of the control $1 \%$ soybean DNA (9.88) was close to $\Delta \mathrm{Cq}$ of the sample Con2 (10.32), in which composition soy flour was declared. In the sample $\mathrm{Cl}, \Delta \mathrm{Cq}$ (15.04) was close to the control sample of degraded DNA (15.62). It is necessary to note that exposure time of the control sample (20 min.) was lower than in production of meat-and-plant canned foods. The comparable degree of
DNA degradation can be explained, most likely, by the low volume and container type, in which the sample was sterilized. $\Delta$ Cq of meat-and-plant canned foods was lower and varied in a range of 12.02 to 12.82 , which is linked with different sterilization regimes for this product category. $\Delta \mathrm{Cq}$ of tofu and preserved tofu also expectedly differed from each other. $\Delta$ Cq was not calculated for the samples C2, Con1, Con3-Con 5 as the positive reaction with the primers Leq1 was not observed in all replicates.

Therefore, $\Delta$ Cq between the values obtained with the primers for single-copy and multi-copy regions was higher when the technological impact on DNA was larger.

\section{Conclusion}

We developed a highly sensitive method for soybean detection in food samples based on selection of a multi-copy region of genomic DNA for primer design. The samples of meat-and-plant canned foods and other samples that underwent deep technological processing were successfully detected by this method. The method showed high sensitivity compared to the use of the primers selected for the singlecopy DNA region: $0.001 \%$ non-degraded soybean DNA for the primers Gly_MAX vs. $0.01 \%$ for Leq1.

During the investigation, a difference in the rate of degradation of the le1 gene region and LTR83118-re-1 was found. This effect can be used for the development of a method for assessing DNA degradation in food products underwent deep technological processing and the following quantitative assessment of the composition.

\section{Acknowledgment}

The work was performed within the framework of the theme of state task No. 0437-2019-0001 «Development of the system of complex assessment of the composition of food products made from raw materials of animal and plant origin».

\section{REFERENCES}

1. Scharf, A., Kasel, U., Wichmann, G., Besler, M. (2013). Performance of ELISA and PCR methods for the determination of allergens in food: an evaluation of six years of proficiency testing for soy (Glycine max L.) and wheat gluten (Triticum aestivum L.). Journal of agricultural and food chemistry, 61(43), 10261-10272. DOI: 10.1021/jf402619d

2. Köppel, R., Dvorak, V., Zimmerli, F., Breitenmoser, A., Eugster, A., Waiblinger, H. U. (2010). Two tetraplex real-time PCR for the detection and quantification of DNA from eight allergens in food. European Food Research and Technology, 230(3), 367-374. DOI: 10.1007/s00217-009-1164-3

3. Costa, J., Amaral, J. S., Grazina, L., Oliveira, M. B. P. P, Mafra, I. (2017). Matrix-normalised real-time PCR approach to quantify soybean as a potential food allergen as affected by thermal processing. Food chemistry, 221, 1843-1850. DOI: 10.1016/j.foodchem.2016.10.091

4. Murray, S. R., Butler, R. C., Timmerman-Vaughan, G. M. (2009). Quantitative real-time PCR assays to detect DNA degradation in soy-based food products. Journal of the Science of Food and Agriculture, 89(7), 1137-1144. DOI: 10.1002/jsfa.3563

5. Ladenburger, E. M., Dehmer, M., Grünberg, R., Waiblinger, H. U., Stoll, D., Bergemann, J. (2018). Highly sensitive matrixindependent quantification of major food allergens peanut and soy by competitive real-time PCR targeting mitochondrial DNA.
Journal of AOAC International, 101(1), 170-184. DOI: 10.5740/ jaoacint.17-0406

6. Mayer, W., Schuller, M., Viehauser, M. C., Hochegger, R. (2019). Quantification of the allergen soy (Glycine max) in food using digital droplet PCR (ddPCR). European Food Research and Technology, 245(2), 499-509. DOI: 10.1007/s00217-0183182-5

7. Pegels, N., González, I., López-Calleja, I., Fernández, S., García, T., Martín, R. (2012). Evaluation of a TaqMan real-time PCR assay for detection of chicken, turkey, duck, and goose material in highly processed industrial feed samples. Poultry Science, 91(7), 1709-1719. DOI: 10.3382/ps.2011-01954

8. Ballin, N. Z., Vogensen, F. K., Karlsson, A. H. (2012). PCR amplification of repetitive sequences as a possible approach in relative species quantification. Meat science, $90(2)$, 438-443. DOI: 10.1016/j.meatsci.2011.09.002

9. Yamakawa, H., Akiyama, H., Endo, Y., Miyatake, K., Sakata, K., Sakai, S., Moriyama, T., Urisu, A., Maitani, T (2007). Specific detection of soybean residues in processed foods by the polymerase chain reaction. Bioscience, biotechnology, and biochemistry, 71(1), 269-272. DOI: 10.1271/bbb.60485

10. Mano, J., Nishitsuji, Y., Kikuchi, Y., Fukudome, S.-I., Hayashida, T., Kawakami, H., Kurimoto, Y., Noguchi, A., Kondo, K., Teshima, R. Takabatake, R., Kitta, K. (2017). Quantification of DNA frag- 
mentation in processed foods using real-time PCR. Food chemistry, 226, 149-155. DOI: 10.1016/j.foodchem.2017.01.064

11. Bauer, T., Weller, P., Hammes, W. P., Hertel, C. (2003). The effect of processing parameters on DNA degradation in food. European Food Research and Technology, 217(4), 338-343 DOI: 10.1007/s00217-003-0743-y

12. Caldwell, J.M., Pérez-Díaz, I.M., Sandeep, K.P., Simunovic, J., Harris, K., Osborne, J.A., Hassan, H.M. (2015). Mitochondrial DNA Fragmentation as a Molecular Tool to Monitor Thermal Processing of Plant-Derived, Low-Acid Foods, and Biomaterials. Journal of food science, 80(8), M1804-M1814. D0I: 10.1111/17503841.12937

13. Wawrzynski, A., Ashfield, T., Chen, N.W.G., Young, N.D., Innes, R.W. (2008). Replication of nonautonomous retroelements in soybean appears to be both recent and common. Plant Physiology, 148(4), 1760-1771. DOI: 10.1104/pp.108.127910

14. GenBank ${ }^{\circledR}$. Bethesda, MD, USA: National Center for Biotechnology Information (NCBI), US National Library of Medicine; 2017. Available from: http://www.ncbi.nlm.nih.gov/

15. Primer-BLAST. Bethesda, MD, USA: National Center for Biotechnology Information, U. S. National Library of Medicine; 2017.
Available from: https://www.ncbi.nlm.nih.gov/tools/primer-blast/ index.cgi

16. OligoAnalyzer 3.1, Integrated DNA Technologies, Inc., Coralville, IA, USA; 2017. Available from: http://eu.idtdna.com/ calc/analyzer.

17. Microsoft Excel 2016, Microsoft, Redmond, WA, USA; 2016. 18. Arun, Ö. Ö., Muratoğlu, K., Eker, F. Y. (2016). The effect of heat processing on pcr detection of genetically modified soy in bakery products. Journal of Food and Health, 2(3), 130-139. DOI: 10.3153/jfhs16014

19. Bauer, T., Hammes, W. P., Haase, N. U., Hertel, C. (2004). Effect of food components and processing parameters on DNA degradation in food. Environmental Biosafety Research, 3(4), 215-223. DOI: 10.1051/ebr:2005005

20. Kostenko, A.A (2015). Methods of production of cheese tofu. Scientific works of Dalrybvtuz, 35, 143-148. (in Russian)

21. Hefle, S. L., Lambrecht, D. M., Nordlee, J. A. (2005). Soy sauce retains allergenicity through the fermentation/production process. Journal of Allergy and Clinical Immunology, 115(2), S32. DOI: 10.1016/j.jaci.2004.12.143

\section{AUTHOR INFORMATION}

Konstantin A. Kurbakov - engineer of laboratory of hygiene of manufacture and microbiology, V. M. Gorbatov Federal Research Center for Food Systems of Russian Academy of Sciences. 109316, Moscow, Talalikhina str., 26. Tel: +7-495-676-60-11. E-mail: homo_ludens@vniimp.ru * corresponding author

Evgenii A. Konorov — candidate of biological sciences, Senior researcher of Laboratory of molecular biology and bioinformatics, V. M. Gorbatov Federal Research Center for Food Systems of Russian Academy of Sciences.109316, Moscow, Talalikhina str., 26. Tel: +7-495-676-60-11. E-mail: casqy@yandex.ru

Valentina N. Zhulinkova - engineer of laboratory of hygiene of manufacture and microbiology, V. M. Gorbatov Federal Research Center for Food Systems of Russian Academy of Sciences. 109316, Moscow, Talalikhina str., 26. Tel: +7(905)780-60-76. E-mail: v.julinkova@fncps.ru

Mihail Yu. Minaev - candidate of technical sciences, head of Laboratory of molecular biology and bioinformatics, V. M. Gorbatov Federal Research Center for Food Systems of Russian Academy of Sciences. 109316, Moscow, Talalikhina str., 26. Tel.: +7-495-676-60-11. E-mail: mminaev@inbox.ru

All authors bear responsibility for the work and presented data.

All authors made an equal contribution to the work.

The authors were equally involved in writing the manuscript and bear the equal responsibility for plagiarism.

The authors declare no conflict of interest.

Received 13.11.2019 Accepted in revised 05.12.2019 Accepted for publication 10.12.2019 